J. J. Thomson's theory makes its moment of momentum exactly equal to em, the product of charge and pole, the charge being measured electrostatically and the pole magnetically.

How can this be shown experimentally? Suppose we had a spinning top enclosed in a case, so that the spin was unrecognisable by ordinary means-it could be detected by its gyrostatic behaviour to force. If allowed to "precess" it will respond by moving perpendicularly to a deflecting force. So it is with the charge and the magnetic pole. Try to move the charge suddenly, and it immediately sets off at right angles. A moving charge is a current, and the pole and the current try to revolve round one another-a true gyrostatic action due to the otherwise unrecognisable ethereal spin. The fact of such magnetic rotation was discovered by Faraday.

I know that it is usually worked out in another way, in terms of lines of force and the rest of the circuit; but I am thinking of a current as a stream of projected charges, and no one way of regarding such a matter is likely to exhaust the truth or to exclude other modes which are equally valid. Anyhow, in whatever way it is regarded, it is an example of the three rectangular vectors.

The three vectors at right angles to each other, which may be labelled current, magnetism, and motion respectively, or more generally $\mathrm{E}, \mathrm{H}$, and $\mathrm{V}$, represent the quite fundamental relation between wher and matter, and constitute the link between electricity, magnetism, and mechanics. Where any two of these are present, the third is a necessary consequence. This principle is the basis of all dynamos, of electric motors, of light, of telegraphy, and of most other things. Indeed, it is a question whether it does not underlie everything that we know in the whole of the physical sciences, and whether it is not the basis of our conception of the three dimensions of space.

Lastly, we have the fundamental property of matter called inertia, which, if I had time, I would show could be explained electromagnetically, provided the ethereal density is granted as of the order $10^{12}$ grams per cubic centimetre. The elasticity of the æether would then have to be of the order $10^{33}$ C.G.S., and if this is due to intrinsic turbulence, the speed of the whirling or rotational elasticity must be of the same order as the velocity of light. This follows hydrodynamically, in the same sort of way as the speed at which a pulse travels on a flexible running endless cord, the tension of which is entirely due to the centrifugal force of the motion, is precisely equal to the velocity of the cord itself; and so, on our present view, the intrinsic energy of constitution of the æther is incredibly and portentously great, every cubic millimetre of space possessing what, if it were matter, would be a mass of a thousand tons, and an energy equivalent to the output of a million-horse-power-station for forty million years.

The universe we are living in is an extraordinary one, and our investigation of it has only just begun. We know that matter has a psychical significance, since it can constitute brain, which links together the physical and the psychical worlds. If anyone thinks that the æther, with all its massiveness and energy, has probably no psychical significance, I find myself unable to agree with him.

\section{SCIENCE AND THE PRACTICAL PROBLEMS} OF THE FUTURE. ${ }^{1}$

$\mathrm{A}^{\mathrm{T}}$ the recent conference on the conservation of resources which met at the White House at the invitation of the President of the United States, notes of warning were sounded concerning the coming exhaustion of coal, wood, ores, and soils. Whether or not we accept as exact the 'stimates furnished by experts on that impressive occasion, there is no doubt that we are approaching the end of our available resources, and that the near future will have momentous problems to face.

Certain things are clear.

First.-Unchecked wastefulness as exhibited, for example, in the extermination of the bison, in the destruction of forests, in the exhaustion of the soil, in the disappear-

1 Abridged from the address delivered by Prof. F. L. Nichols, the retiring the Baltimore meeting, December, rgo8.

No. 2046, VOL. 79] ance from our coasts and streams, that once teemed with fish, of this important source of food supply, in the pouring into the air of an incredible amount of unused fuel from hundreds of thousands of coke ovens, must cease, or our ruthless exploitation will bring disaster on generations soon to come. The prevention of these and countless other manifestations of individual and corporate greed is a problem for the economist and the law-maker, although they will scarcely succeed in its solution without calling science to their aid.

Second.-Saving and thrift offer at best only a postponement of the day of distress. The end of our supplies of coal and petroleum must ultimately be reached. Forests may be renewed and the soil restored to its maximum fertility, but the problem which is presently to confront the race is that of civilised existence without recourse to energy stored by the slow processes of nature. This problem must be definitely solved before the complete exhaustion of our inherited capital.

Third.-The problem is not without conceivable solution, since the annual accession of energy from the sun, did we know how to utilise it without awaiting the slow processes of storage employed by nature, is ample for every thinkable need of the future inhabitants of our planet. Estimates of the constant of solar radiation show that about $2 \cdot 18$ kilowatts of power is continually received from the sun for every square metre of the earth's surface, or more than seven and a half millions of horse-power per square mile. The present use of power in the United States is about eighty million horse-power, or one horsepower per capita. This quantity is likely to increase more rapidly than the population in the future unless curtailed by lack of fuel, but it is evident that a very small fraction of the sun's radiation would meet all demands.

Now abundant power is soon to be the factor upon which material advancement will chiefly depend. To obtain it in the face of the disappearance of coal and petroleum will be imperative. For success in this, upon which in the immediate future the welfare of the race and ultimately its very perpetuity is to depend, we must look to science. Mere ingenuity or inventiveness, however widely developed, will not suffice. The inventor and the engineer can but utilise and apply the material which the man of science provides, and with the exhaustion of our stores of scientific knowledge civilisation must halt.

It is of this fundamental relation of science to the progress of our civilisation that I wish to speak. The fact that material progress is based upon science seems to be but dimly understood. It appears to be generally supposed that it is to the inventor and to those who use his devices that we owe our present advantages over our forefathers. I would not belittle the achievements of the socalled practical man, but the public must be taught that application can never run ahead of the knowledge to be applied, and that the only road to higher achievement in practical things is by the further development of pure science.

The main product of science, using that word in its broadest sense, is knowledge; among its by-products are the technological arts, including invention, engineering in all its branches, and modern industry. Not all industries have attained the character of a technological art. Burning the woods to drive out game, and thus obtain a dinner, is a form of industry. Like it in character are some very large industries, such as agriculture of the sort that impoverishes the soil; lumbering that destroys forests, and incidentally ruins rivers and increases erosion; cokemaking by processes that waste 40 per cent. of the energy of coal. The production of power from coal by means of the steam boiler and the reciprocating engine we at present regard as a highly developed technological art; yet it is a process which, at the very best, converts less than ro per cent. of the total stored energy of the fuel into available form. If the ultimate purpose of this power is the production of light, we by our present methods suffer a second waste of 90 per cent. or more, so that the efficiency of the combined processes is but a fraction of I per cent. These things are excusable while ignorance lasts. They become criminal with realisation of the results, and are inconceivable in a community of fully developed civilisation. Science paves the way for the gradual sup- 
planting of these barbarous methods by more refined and rational processes, but they often persist long after they are known to be injurious to..the public...welfare because they happen to serve some selfish individual or corporate purpose. In such cases it is to science again that we must..look for the development of an enlightened public opinion that will end them.

A country that has many investigators will have many inventors also. A scientific atmosphere dense enough to permeate the masses brings proper suggestions to many practically inclined minds. Where science is there will its by-product, technology, be also. . Communities having the most thorough fundamental knowledge of pure science. will show the greatest output of really practical inventions. Peoples who get their knowledge at: second-hand must. be content to follow. Where sound scientific conceptions are the common property of a nation, the wasteful efforts of the half-informed will be least. prevalent. . The search after perpetual motion, the attempt to evade the second law of thermodynamics; and the promotion of the impracticable are all-simply symptoms of a people's ignorance.

Modern invention is a very near neighbour to the pure science of the laboratory, and the relation becomes daily more intimate. Nothing could apparently be more academic in its early development or further from the practical workaday world than the subject of electric waves. For years it was regarded as a fine field for the speculations of the mathematical physicist. Then at the hands of Hertz and his followers it became a fascinating topic for experimental investigation by men devoted to science for its own sake. Suddenly it was launched into the realm of hard-headed commercialism by a.practical man, daring, enthusiastic, and optimistic enough, at a time when electric waves could be produced in one room of the laboratory and detected in the next room, to dream of sending such waves across the sea as bearers of human messages.

At every step of its development the things that have made wireless telegraphy possible have been borrowed from pure science.

While Marconi was still struggling to adapt the apparatus of Righi to long-distance transmission, the antenna and the coherer were already in use by Popoff in the study of oscillatory lightning. In the thermal detector of Fessenden the almost invisible platinum wires produced years before by Wollaston for the cross-hairs of telescopes appear in a new field of usefulness. The "lead-tree" familiar as a simple and beautiful lecture experiment in electrolysis forms the basis of the responder of De Forrest. Another form of electrolytic detector, introduced independently as the receiver of wireless signals by Schloemilch and by Vreeland, traces back to the Wehnelt interrupter. Marconi's latest receiver, the magnetic detector, is an ingenious modification of Rutherford's device for the study of electric waves, and this in turn was based on the classical experiment of Joseph Henry on the effects of the discharge of Leyden jars on the magnetisation of steel sewing needles.

It is needless to multiply examples. In the history of science and of invention this intimate relation appears to be almost universal. The environment of science has always been academic. Science has its home in the university. From Galileo and Newton to our own time the men who have laid the foundations upon which civilisation is built have nearly all been teachers and professors.

A few notable exceptions there are, such as Darwin, whose centenary we are about to celebrate. Each branch has its short list of unattached investigators-Franklin, Rumford, Carnot, Joule in physics, \&c.-but the honourroll of science is essentially an academic list.

It is necessary, in considering the place of America in science, to contrast the standing of its educational institutions, not pedagogically, but as centres of research, with those of other countries. The United States has less than its share of men of 'science, because it has not, as yet, universities that sufficiently foster and encourage research. When in any of its institutions a man distinguishes himself by productive work, he is frequently made a dean, director, or even president, and is thus retired from what might have been a great carear as an investigator. There- after he is compelled to devote himself to administrative duties, which someone not equipped for the important task of adding to the world's stock of . knowledge might just as well perform. It is as though the authorities were to say, $\mathrm{X}$ has written an admirable book, we must appoint him book-keeper; or $\mathrm{Y}$ is developing a decided genius for landscape, we will increase his salary and ask him to devote all his time to painting the woodwork of the university buildings. Nor does the mischief stop with the sacrifice of a few bright spirits. It extends to the bottom. The head of each department is a petty dean, cumbered with administrative detail. He is expected to hold everyone under him to account, not for scholarly productiveness, but for the things which chiefly hinder it.

In this exaltation of administrative ability over creative gifts, which are much rarer and more precious, our institutions share the weakness which pervades our ' in dustrial establishments, where the manager or superintendent usually gets larger pay and is regarded as more important than the most expert craftsman. In both we see the same striving for a certain sort of efficiency and economy of operation and for the attainment of a completely standardised product. This tends in both cases to the elimination of individuality and to sterility. In the university it retards instead of developing research. In industry it discourages originality. I would that there might be displayed in the administrative offices of every institution of higher education this testy remark, once made by an eminent scholar:- "You cannot run a university as you would a saw-mill!"

If anyone questions the responsibility of the American university for the shortcomings of American science, and is inclined to seek some more obscure cause for the conditions that I have endeavoured to portray, let him consider the history of astronomy in the United States. This science, for some reason, was from the first accorded favours not vouchsafed to any other branch of learning. Colleges that made no pretence of research, and had neither laboratories nor libraries worthy of the name, were ambitious to have observatories, and rich men were found to establish and endow them. The observatory implied, somehow, to the minds of the authorities an astronomer - not merely someone of good moral character who could teach the' subject-and so it came about that there was one member of the college faculty who was expected to do scientific work, and was left comparatively free to observe and investigate. Mode'st as most of these early provisions for astronomy were, they bore fruit, and American astronomy gained standing and recognition while her sister sciences were struggling for existence. Later, it is true, there arose an ambition for laboratories, and there were laboratories; but, unfortunately, save in very rare instances, the laboratory has not implied an investigator. The conditions which made astronomy what it was have not been repeated. Productiveness has, not been demanded nor expected; neither have the inmates of our laboratories been accorded that exemption. from excessive pedagogical duties which would enable them to yive their best strength to research.

A recent event in the educational world well illustrates the weakness of our academic attitude toward science. The head of one of our strongest, most modern, most progressive, and best equipped institutions has announced, as one of the details of a noble bequest to the University, the endowment of ten research professorships. President Van Hise declares :-

"The provisions for their support, including liberal salaries, assistants, materials, a limited amount of instructional work, and relations with students, are an epitome of the situation in the best German universities, which are admitted to stand first among the institutions of the world in the advancement of knowledge."

This is indeed an event to warm the heart of everyone who is interested in the promotion of science. . All who are devoted to learning for its own sake or who realise the importance of science to the welfare of the nation will applaud that portion of the will in which this great gift is made, which reads :-

"The university may best be roised to the highest cxcellence as a seat of learning and education by abundant support in pushing the confines of knowledge." 
Yet in very truth there is nothing to prevent the University of Wisconsin, or any other of a hundred like institutions, without awaiting the rare advent of some farsighted benefactor, from having, not ten, but all her professorships made research professorships-nothing, alas, but the deep-seated and seemingly uneradicable conviction of the boards of control, that the endowments committed to their charge are for some other purpose.

A true university from the point of view of scientific productiveness is a body of scholars, that is to say, of men devoting themselves solely to the advancement of learning. Everyone in it, from top to bottom, should be an investigator. The entire income of a university should be expended in the promotion of science, i.e. of knowledge. Teaching is a necessary factor in the advancement of learning, and so a function of the university. University teaching should be done by investigators, not only because more investigators are to be developed, but because the promotion of science, on the scale which the future demands, means that science shall not remain narrowly academic, but shall more and more pervade the life of the people.

From the point of view of American institutions such a definition of the university is revolutionary, but it cannot be said to be impracticable or Utopian, for upon precisely such ideals the most successful university systems in the world have been built.

That this type will bear transplanting to American soil was triumphantly demonstrated in the work of Daniel C. Gilman, who gave the Johns Hopkins University at its inception the essential characteristics of the German universities as regards research. This successful experiment should have marked an epoch in the history of higher education, but a generation has passed and we have not as yet a university system devoted primarily to the advancement of learning. We still consider investigation merely as a desirable adjunct to university activities, never as the thing for which the university exists.

Germany, on the other hand, has for a century consistently developed the university as a centre of research, and through the promotion of pure science in the university has made German civilisation what it is to-day.

I would not be understood as urging German or other European methods in all details upon a country where quite different conditions exist, but one general principle is of universal application. In whatever we have to do, whether it be municipal administration, sanitation, roadmaking, the construction of water-ways, the development of industries, or the conservation of natural resources, the fullest and latest scientific knowledge should be utilised. Practice should not be permitted to lag indefinitely behind theory, and that they may go hand in hand public work and private enterprises should be in the hands of those who know. At the same time, science should be persistently advanced by every possible agency.

To my mind, the future of science in America, as elsewhere, is essentially a question of the future of the universities. It is conceivable that institutions may so long continue blind to their chief function as to be supplanted by some new agency called into existence to take up their neglected work. Already great endowments for the promotion of research, quite without any pedagogical feature, have come into existence. For all such science has need, and will have increasing need, as the situation becomes more acute and we are brought closer to the great crisis.

But it will be found that the conditions for maximum scientific productiveness are precisely those which would exist in the ideal university. All attempts at a machinemade science are doomed to failure. Science-making syndicates are likely to meet shipwreck on the very rocks on which the American educational system is already aground. No autocratic organisation is favourable to the development of the scientific spirit. No institution after the commercial models of to-day is likely to be generously fertile. You can contract for a bridge according to specifications. If a railway is to be built and operated, a highly organised staff with superintendents and foremen and an elaborate system reaching every detail may be made to yield the desired results. No one, however, can draw up specifications for a scientific discovery. No one can con- tract to deliver it on a specified day for a specified price. No employee can be hired to produce it in return for wages received.

T'o the investigator the considerations I have endeavoured to present are unimportant. Science for its own sake is his sufficient incentive; but it is all-important for the community at large to realise that no real addition to knowledge is useless or trivial; that progress depends on scientific productiveness; that science, which must be fostered if we are to continue to prosper, is a republic the watchwords of which are liberty, equality, fraternity.

World power in the near future is to be a question of knowledge-not of battleships-and what is now spent on armaments is to be devoted to its pursuit. Beyond lies that future in which it will no longer be a question of supremacy among nations, but of whether the race is to maintain its foothold on the earth.

\section{UNIVERSITY AND EDUCATIONAL INTELLIGENCE.}

To perpetuate the memory of the late Sir George Livesey it is proposed to endow a Livesey professorship in gas engineering and fuel at the Leeds University. The committee having the matter in hand announces that contributions to the fund should be sent to the secretary of the Institution of Gas Engineers, 39 Victoria Street, Westminster. A sum of at least ro,oool. is required for the object in view.

THE University of Liverpool has received an offer from Mr. Alexander Elder, of Southport, formerly of Elder, Dempster, and Co., Liverpool, to contribute 12,50ol. for the establishment of a chair of naval architecture in the University. The proposal will be considered by the University council at its next meeting. The foundation of such a professorship would of necessity mean a great expenditure in fitting and equipping lecture-rooms and laboratories, and in maintaining the work of the new department. It is hoped that other gifts will be forthcoming to make it possible for the council to accept $\mathrm{Mr}$. Elder's generous offer.

The Rev. Lord William Cecil is proceeding to China at the request of an influential committee of graduates of Oxford and Cambridge to try to found a Christian and educational university there. At present much educational work is being done by the American missions, but very little by the English. It is thought that one union university will be more efficient and more economical than many smaller establishments working without method. It is hoped to avoid the difficulties of divergent religious teaching by founding a university on the lines of Oxford and Cambridge. While each college of the university will be under the control of some mission body, the university itself, like Oxford and Cambridge, will not be attached to any one denomination. The university will concern itself chiefly with the teaching of arts, science, and engineering. The university is not intended to be a permanent foreign settlement in China. With the growing body of Chinese Christians, it is expected that the chairs may be filled soon with those who have been students in the university.

WE have received a printed copy of a lecture delivered by $M$. Jules Gautier, director of secondary education in France, last October, under the auspices of the British Education Section of the Franco-British Exhibition, on the Education Section of the Franco-British Exhibition, on the of Napoleon I. It is interesting to notice in the lecture that science was introduced in the curriculum of French secondary schools so far back as 1821 , while in 1829 the idea was prevalent that Latin and science formed a suitable training for young men wishing to enter the Army or the Diplomatic Service. In $185^{2}$ the system was introduced of dividing pupils, after the preliminary stages, into two groups, those who wanted a literary or classical education and those who wanted a scientific education, but this system was short-lived. It was not until 1902 that the present system was inaugurated. To-day French secondary education is divided into two cycles; the first is concerned with the years from ten to fourteen, and the second with the remaining school years. In the first cycle science is 